\title{
Research productivity of Australian planning academics: A bibliometric analysis
}

\author{
Authors \\ Dr Dorina Pojani, The University of Queensland, Australia, d.pojani@uq.edu.au \\ Mr Jaime Olvera-Garcia, The University of Queensland, Australia, j.olveragarcia@uq.edu.au \\ Prof Neil Sipe, The University of Queensland, Australia, n.sipe@uq.edu.au \\ A/Prof Jason Byrne, Griffith University, Australia, jason.byrne@griffith.edu.au
}

\begin{abstract}
The development of global metrics for evaluating university research performance has been accompanied by increasing attention to key performance metrics for individual disciplines. This paper examines research performance metrics for Australian planning academics. It addresses questions related to programs, staff, publications, and citations. The main findings are the following: wide gender gaps exist in Australian planning academia; the mean number of publications is 36/person or 3/person/year; the mean number of citations is 527/person or 48/person/year; and planning journal impact factors are low (less than 3).
\end{abstract}

This is an Authors' Original Manuscript of an article whose final and definitive form, the Version of Record, has been published in Journal of Planning

Education and Research (JPER), 2018, copyright Sage, available online at: http://journals.sagepub.com/doi/pdf/10.1177/0739456X18804330

\section{Keywords}

Citation analysis, bibliometrics, research performance, planning, Australia.

\section{Acknowledgement}

This research was funded through a grant by the University of Queensland. 


\section{Introduction}

Global universities now operate within a framework that some scholars have described as 'neoliberal' - the competitive pursuit of efficiency and excellence in the drive for prestige and increased income (Batterbury and Byrne 2017). Accompanying this shift, the evaluation of university research performance based on key metrics, including publications and citations, has become a global practice. Four rankings - the Shanghai Jiao Tong University Academic Ranking of World Universities; the Times Higher Education and QS World University Rankings; and CWTS Leiden Ranking, now exert considerable influence on academic research investment and funding decisions (Hicks 2012). Individual universities, departments, and scholars are under increasing pressure to improve their standing on the world stage (Jöns and Hoyler 2013, Taylor and Braddock 2007).

In this article, we benchmark research performance metrics for Australian planning academics, investigating the impact of the global shift to performance-based assessment. Australian universities, like many international counterparts, are now funded under competitive, performance-based funding arrangements (see Batterbury and Byrne 2017). While comprehensive assessments of publication and citation metrics exist for the United States (see Sanchez 2017, 2016; Stiftel et al. 2004), less is known about other centres of planning scholarship, presenting an important knowledge gap. Our research has been guided by the primary question: "In a performance-based environment of benchmarking research excellence, what factors account for differences in research productivity (publications, citations and grants) among Australian planning scholars?". A key finding is how the combination of historical patterns of gendered labour in the Australian academy (mirroring those internationally), may be combining with contemporary performance-driven indicators of publication, citation and grant-winning, to disadvantage less senior, female academics.

As a discipline, planning research productivity is oftentimes unflatteringly compared with the sciences. Sanchez $(2014,2017,2016)$ for example, has shown that science-based aggregators of publications and citations (e.g. Web of Science, Scopus) report fewer publications and citations than Google Scholar. Planners may be disadvantaged if hiring and tenure committees rely on the former rather than the latter. This is because Google Scholar also includes "non-traditional" publications (e.g. reports) outside scholarly sources. Although such "grey" literature is seldom peer-reviewed, its inclusion in citation metrics reflects its greater reach and impact compared to pay-wall-protected publications. Our research therefore compares Google Scholar and Scopus metrics. Google Scholar is most commonly used by Australian planning academics when applying for tenure, promotions or grants.

The paper reports findings against four core areas:

- Programs: How many planning programs are there in Australia?

- Staff: What is the distribution of planning academics among ranks and are there gender differences in this distribution?

- Publications: How much 'scholarship' do planning academics produce? What variances are there by institutional standing (e.g., membership of Group of Eight or Go8 universities $)^{1}$, and why? How does productivity change as academics progress through their careers? Are there differences by gender? What impact factors do the most popular peer-reviewed planning journals have?

- Citations: How often is the work of planning academics cited? What variances are there by 
institutional standing (e.g., membership of Group of Eight or Go8 universities), and why? How does impact (citation counts) change as academics progress through their careers? Are there differences by gender? How does Australia compare to major centres of planning scholarship, such as the US?

Benchmarking research performance is important not only because it can affect an individual's opportunities for tenure and promotion, and mental wellbeing, but judgements made on research performance can impact departmental income, morale and reputation. This matter is especially salient for Australian planning programs, because they tend to be small and are often part of large interdisciplinary schools, which can include architecture, geography, political science, information technology, engineering and/or environmental science. Planners can find themselves disadvantaged if faculty administrators do not recognise that these disciplines apply different metrics to the "measurement" of academic performance.

\section{Background}

In a hyper-competitive global education market, research productivity and performance are seen as important ways to distinguish between the relative standing of different institutions; they have become proxy measures for the quality of teaching and course offerings (Byrne 2017). The use of "performance metrics" has emerged as the principal way to assess "quality" (Goldstein and Maier 2010; Arimoto 2011; Linton et al. 2011). For planning academics, the main forms of research output include books, book chapters and journal articles, but also professional reports, conference papers, studio/workshop projects, blog entries, and other electronic media (Sanchez 2017). Nearly all these products involve the retrieval and review of previously produced works as part of the process of creating new knowledge. Relevant items are cited for their authority and/or context (including examples of alternative ideas or conclusions). This process generates a network of citations that can be both quantitatively and qualitatively evaluated. With the advent of the Internet, citation data can easily be retrieved online from indexes such as Scopus, Web of Science, and Google Scholar.

It is important however, to recognize that the practice of ranking academics based on research performance metrics (e.g., number of publications, journal impact factors, citations, research income), is peculiar to the present time, and is not ideologically "neutral." Metrics are seldom undergirded by intellectual, political, or moral theory; they carry a strong normative bias. As Neil Postman (1993) noted in Technopoly, embedded in such numbers is "a predisposition to construct the world as one thing rather than another, to value one thing over another, to amplify one sense or skill or attitude more loudly than another." The use of metrics to rank people - first university students $^{2}$ and now academics - is reshaping what is meant by 'quality'. Ranking practices can affect deeply embedded habits of thought, and privilege particular ontologies and epistemologies of knowledge production to the exception of others. Recent performance-based ranking practices, for example, represent a paradigm shift, ousting subjective forms of evaluation that have traditionally guided academic practice. If we simply accept the hegemony of numerical rankings in academia, scholars risk becoming, in Henry David Thoreau's (1854) words, "tools of our tools." Standardized metrics are reductionist and obscure nuance, complexity, detail, and ambiguity in scholarly outputs. They provide only a limited range of formal, objective, and impersonal information. Yet many contemporary performance evaluation and promotion committees believe that without numbers they cannot accurately assess an academic's performance. 
In Australia, as elsewhere, such metrics have rapidly become the normal way of assessing academic performance (Byrne 2017). They play a substantial role in both confirmation of tenure and application for promotion. Given the consequences for Australian universities of reduced federal funding from sub-optimal performance (e.g., not being able to maintain research facilities, failing to attract international students), Australian scholars are generally under considerable pressure to "publish or perish" (Sanchez 2017). Australian academics are regularly counselled about how to cultivate increased citation of their publications (Innovative Research Universities 2018). This includes publishing in open-access journals, publishing alongside international scholars from prestigious institutions, maintaining an online Google Scholar profile, and participating in public engagement via social and mainstream media. Although in 2011, the Australian Research Council (ARC) - the national research funding agency - ceased rating peerreviewed journals for the Excellence in Research for Australia assessment, such metrics have become institutionalised within managerialist business practices of Australian universities as they compete in a global education market (Connell 2015; Byrne 2017). Education is now one of Australia's top exports, earning the country nearly AUD\$30 billion annually (Australian Financial Review), so demonstrating research excellence is 'serious business'.

\section{Practical Shortcomings of Academic Ranking and Metrics}

While publication and citation counts, impact factors, and h-indexes are said to represent the impact and influence of academic output over time, in additional to the conceptual inadequacies noted earlier, these metrics have recognised practical shortcomings. We briefly review these, before turning to the assessment of Australian planning research output. We do so because it is important to acknowledge limitations when undertaking this type of analysis.

Citation counts are either reported on their own or used to compute other metrics (e.g., impact factors and h-indexes). Context is important. In planning and other branches of academia, nonscientific factors influence the decision to cite. Many citations are used simply to validate an article's introduction, having no real significance to the rest of the work. Articles that focus on fashionable topics can improve citation chances. Considerable citation bias exists in favour of review articles. Well-established scholars are cited disproportionately more often than lesserknown scholars (so-called "gratuitous authorship"). Many authors tend to cite their own close colleagues more than others (i.e., "publication cartels"). Citations may oftentimes stem from negative or critical assessments (e.g., identifying flaws in prior research) - yet this is not factored into metrics (Bornmann and Hans-Dieter 2008; Hyland 2016).

First devised in 2005, the $\underline{h \text {-index }}$ attempts to measure both the productivity and citation impact of the publications of a scholar. An h-index of 10, for example, indicates that an author has published 10 papers, each of which has been cited at least 10 times (Hirsch 2005). As citation counts, the hindex is also misleading. It is generally effective only for comparing researchers working in the same field - citation conventions differ widely among different fields. This is problematic for planning programs, which are embedded in multi-disciplinary schools. Planning itself is so diverse that h-indexes can vary substantially (e.g., between urban transportation, health issues, or planning history). Moreover, the h-index fails to distinguish the relative contributions to the work in multiauthor articles, and does not reflect the length of time an academic has been publishing. Junior or early career researchers typically have lower h-indexes. Moreover, the h-index captures only part of a scholar's publication and citation data; it fails to represent highly and rarely cited or non-cited papers. Academics with very different citation frequencies can have the same h-index. For 
example, two academics with an h-index of 10 may each have 10 papers with 10 citations, but one may have an additional 90 papers with 9 citations each, which are unaccounted by the index; or one may have exactly 10 papers with 10 citations each and the other exactly 10 papers with 100 citations each (Bornmann and Hans-Dieter 2009). To correct for this, Google Scholar has recently introduced a complementary i10-index (the number of publications with at least 10 citations).

The Clarivate Analytics ${ }^{3}$ impact factor (IF) of an academic journal is a measure reflecting the annual average number of citations to recent articles published in that journal (e.g., in the last two years). Typically, it is used as a proxy for the relative importance of a journal within its field. Owing to its availability and utility, promotion committees, funding agencies, and scholars often also use it as a shorthand assessment of the quality of individuals or institutions. IFs were instituted as early as 1975 (initially as a way for librarians to make more informed decisions about journal subscriptions). However, IFs are misleading and can distort the communication of scientific progress due to selective attention to publications in high-ranking journals (Brembs et al. 2013).

When impact factors are used to evaluate individual papers rather than journals, this devalues papers in subjects such as planning - as IFs of planning journals are comparatively low (e.g., 2-3) compared to STEM disciplines (e.g., 50). As with the h-index, the IF is affected by field-dependent factors and cannot be used to compare journals across disciplines, or even between planning subdisciplines (e.g., environmental planning and urban design). A high IF can be the skewed result of self-citation, within-journal citations, or many citations of just a few articles (e.g., review articles or articles led by well-known senior researchers) rather than the average level of the majority, reducing its value as an objective measure. Some commentators contend that self-citation is less of a concern for individual authors than for journal impact factors. The latter are more susceptible to self-citation because relatively small numbers of citations can produce a significant change (Stevens 1990; Harzing 2010).

Commentators have also noted that many academics are now more concerned about publishing in high-IF journals than they are about the social impact of their research (Batterbury and Byrne 2017). Moreover, the practice of submitting articles to journals at the top of the IF ladder, circulating progressively through journals further down the rungs when they are rejected can be a waste time for both editors and reviewers (Campbell 2008; Simons 2008). Because not all journals are assigned an IF by Clarivate Analytics, publishers have begun to devise other indexes, including CiteScore $^{\mathrm{TM}}$, RIP (Raw Impact per Paper), SNIP (Source Normalized Impact per Paper), and FWCI (Field Weighted Citation Impacts), which are more transparent and/or attempt to account for the differences in research behaviour across disciplines. However, these esoteric metrics are also vulnerable to manipulation.

Alternative metrics. Planning is a professional discipline. Not only do academics generate scholarly research outputs, but they are also expected to contribute to professional practice, guide sustainable development, and connect directly with local communities through service and outreach (Spain 1992; Wiewel et al. 1996; Krumholz 1986). As such, planning research performance cannot be solely measured through standardized academic metrics (Sanchez 2014; Wachs 1994). Underscoring this limitation, alternative new metrics have emerged, such as Webometrics $^{\mathrm{TM}}$, Altmetrics ${ }^{\mathrm{TM}}$, Academia.edu, and ResearchGate. These have the potential to capture and assess a broader range of scholarly impact than traditional citation analysis and bibliometrics (Kousha and Thelwall 2007; Aguillo 2011; Priem et al. 2010). Webometrics assess "informal" impact, which is primarily associated with educational impact (e.g., citations in course syllabi posted online), scholarly presentations (at conferences or seminars), and blog impact 
(Kousha et al. 2010). Altmetrics include measures of usage, in addition to "formal" citations: downloads, views, shares on social media, bookmarks, expert reviews, user comments, and forum discussions (Kousha et al. 2010; Priem et al. 2010). Sites such as Academia.edu and ResearchGate serve as alternative repositories of academic products and employ their own metrics and analytics (e.g., online traffic overview and RG Score).

Alternative metrics are particularly important for planning academics given a range of grey literature (e.g., reports) they produce (Sanchez 2014; Hurt and Yin 2006). However, in practice, achieving high alternative scores requires academics to spend considerable time curating and updating social media profiles, self-promoting, and cultivating online personas. Assessing the impact of public service may be even more difficult than measuring traditional scholarship. Planning processes tend to be slow and the impact of academic work might take years or decades to materialize. Moreover, positive urban change is rarely the outcome of solitary visionaries; it typically owes to the joint efforts of planning academics and practitioners (Frank 2008; Checkoway 1997).

\section{Methods}

We have employed similar methods to those used by Sanchez (2017) in his assessment of the US planning academy. To answer the research questions we outlined in the introduction, we have used four sets of data about planning programs/academics in Australian universities - accredited programs, staff, publications, and citations. The study timeline was 2006 through 2016, a time period reflecting the implementation of performance assessment metrics in Australia (Innovative Research Universities, 2018). Since our data were collected in 2016, some planning academics have changed positions (parallel moves to a different university, promotions within the same university or both a move and a promotion) or left Australia, and new academics have been recruited from abroad in some planning programs.

\section{Programs}

Data on the number of accredited planning programs offered by Australian universities were obtained from the Planning Institute of Australia (PIA). PIA is Australia's professional association of planning practitioners and academics and accredits planning programs. While undergraduate and graduate programs are noted separately, they are not different faculties, but they are different degrees. Unlike most universities in the United States, where planning qualifications are at the Masters (postgraduate) level, some Australian universities offer both undergraduate planning degrees and Masters (requalification) degrees.

\section{Staff}

Because most planning programs are embedded in interdisciplinary schools and their courses are taught by academics with a variety of backgrounds (many of whom do not self-identify as

planners), ascertaining reliable numbers was difficult. A list of all academics affiliated with planning programs was created based on the information from university websites. That list included individuals that did not appear to have a strict planning background but taught into planning programs. Program coordinators and/or directors of all accredited planning programs were then contacted (via email or telephone) to confirm the number of academics in their program, and the list was modified accordingly. ${ }^{4}$ 
In Australia there are five academic ranks: (A) Associate Lecturer; (B) Lecturer; (C) Senior Lecturer; (D) Associate Professor; and (E) Professor. ${ }^{5}$ The metrics for staff members not on a traditional academic appointment (i.e., Research Fellows / Senior Research Fellows) were also calculated. ${ }^{6}$ Teaching Fellows were excluded, because they typically do not produce research.

\section{Publications}

For those academics appearing on the list, data were collected for the past decade - 2006 through 2016. A list of publications was generated from the staff profile on university webpages, Google Scholar, and Publish or Perish, and was then cross-referenced to ensure accuracy. Publication types included: peer-reviewed journal articles; book chapters; edited books; authored books; and conference papers (both peer-reviewed and non-peer-reviewed as it was difficult to distinguish between the two). Publications and citations were then aggregated by: (i) program; (ii) publication type; (iii) academic rank; and (iv) gender (male/female only). Both totals and averages were computed; publication metrics were correlated with citation metrics. As part of this process, the top twenty journals in which planning academics publish along with their impact factors were also identified.

\section{Citations}

Citation data were obtained via Google Scholar and Publish or Perish, by visiting the profiles of each individual on the list of planning academics. At the time of writing, a surprising number of planning academics - 71 out of 196 (36\%) - did not have a Google Scholar profile. The distribution of those without a Google Scholar profile was about equal across ranks. It is possible that academics who are more productive, and whose work is more highly cited, are more likely to have public Google Scholar profiles. Also, younger academics may be more likely to curate their web presence. And several academics have transitioned to retirement since our data was collected and analysed, or moved universities. For academics without a Google Scholar profile, publication/citation data were obtained through university website profiles and Publish or Perish.

\section{Bibliometrics: Google Scholar vs Scopus}

The same process, and for the same list of planning academics and the same timeframe (20062016), was repeated to extract publication and citation from the Scopus database. About $6 \%$ of planning academics (12 in total) did not have as Scopus profile. In that case, publication/citation data were obtained through Publish or Perish. These data are compared, in aggregate form, in Table A-6 in the Appendix.

\section{Results}

We report our results and answer the research questions set forth at the outset using the same parameters identified in the methodology above (programs, staff, publications, and citations). In a final section on bibliometric analysis, we provide empirical evidence for our argument that in the case of planning, Google Scholar is preferable to other aggregators, such as Scopus.

\section{Programs}

How many planning programs are there in Australia?

A total of 48 accredited planning degrees at 24 universities were identified, staffed by 196 planning 
academics (Table A-1). ${ }^{7}$ Planning programs are clustered along the southeast coast of Australia, where most large cities are located (Figure A-1). Among the Group of Eight (Go8) universities (the most prestigious universities in Australia, comparable to elite institutions in other countries), only six offer planning programs: University of Western Australia, University of Adelaide, University of Queensland, University of Melbourne, University of New South Wales, and University of Sydney. Monash University and Australian National University do not currently offer planning courses (although Monash is in the process of opening a postgraduate planning program).

\section{Staff}

What is the distribution of planning academics among ranks?

There are few Associate Lecturers in planning, as these appointments are typically made at prePhD level (Figure 1). Also, fewer than 10\% of planning academics have research-only positions. Research-focused appointments are clustered in a few universities, which have established planning research centres as part of an institutional strategy for improving research performance. ${ }^{8}$ No strong pattern can be discerned in the distribution of the remainder academic ranks (Lecturer through Professor). While there are more junior academics (Lecturers and Senior Lecturers) than senior academics (Associate Professors and Professors), the differences are not striking. This is partly explained by the fact that promotions in Australia are based on individual merit. The situation differs considerably in some European countries, where rigid pyramidal hierarchies are maintained with a single Professor leading a research group. That system constitutes a significant barrier to the career progress of junior planning academics.

What are the gender differences in the distribution of planning academics among ranks?

In regards to gender equity, the data reveal significant disparities (Figure 2). Overall, males outnumber females: $109(56 \%)$ vs. 87 (44\%). Females are overrepresented in junior positions (lecturer ranks) but underrepresented in senior positions (professorial ranks). While women represent the majority in research-only positions, these are however few, as noted, and not always tenured.

\section{Publications}

How much do planning academics produce?

Between 2006 and 2016, Australian planning academics produced a total of 7,038 publications, comprised of journal articles, conferences papers, books, and book chapters. Overall, the median number of publications was 26.2 per person and 3 per person per year (Table A-2).

\section{What variances are there by institutional standing and why?}

While having $31 \%$ of planning staff, Go8 universities contributed $39 \%$ of the total publications produced during the study timeframe. The variances are noted in Table A-2. Obviously, universities employing more planning academics have an advantage in total output even where individuals are not as productive. For example, the University of New South Wales, which has the most planning academics (21), also has the most total publications $(1,065)$. However, the mean per academic is much smaller there than at the University of Melbourne (50.7 vs. 76.3), which has produced fewer publications in total (687) due to its smaller faculty size (only 9 members). The University of Sunshine Coast has a high mean (49.3), despite having just 3 planning faculty 
members.

Because not all planning academics produce at the same rate, means can be misleading. In some cases, a few individuals produce a disproportionally large number of publications. This is especially true among the top ten most productive schools. The most outstanding example is at Queensland University of Technology where one academic has contributed more than 200 publications during the study period. Other universities where an individual academic has contributed 80 or more publications during the same period include: University of New South Wales, Griffith University, University of Melbourne, and Western Sydney University. If these productive academics were omitted from the calculations, the annual and total means would be significantly lower. Only one university, University of Melbourne, ranks in the top five on all publication metrics - totals, means, and medians.

Among the top ten universities in Table A-2, four belong to the Group of Eight (Go8): University of New South Wales; University of Melbourne; University of Queensland; and University of Western Australia. This finding suggests that, in the case of planning, it is important to look at the performance of individual programs rather than assume that a "brand name" university will automatically include a top planning program (as determined by productivity). From a student's perspective, the scholarly reputation of academics is not the only criterion to consider when deciding where to study planning. In fact, teaching quality, curriculum offerings, and average class size might be more important to prospective students than the academic output of their instructors. This study did not examine whether these factors correlate with the quantity and quality of publications produced by planning academics, but Griffith University has recently been recognised as the top in the nation for student satisfaction. ${ }^{9}$

\section{How does productivity change as academics progress through their careers?}

On average, the number of publications increases as academics progress through the ranks (Figure 3). However, the progression is not linear; output tends to plateau once individuals reach the top rank of Professor (see also Riordan 2011). If one looks at the mean number of publications, it is actually higher for Associate Professors than Professors, while the median is slightly lower. This discrepancy is most likely explained by the presence of a few highly productive Associate Professors who have not yet been promoted to Professor, or perhaps by increasing leadership service obligations at the highest rank.

The difference in output between Research Fellows and Senior Research Fellows is striking. While Research Fellows publish as much as Lecturers, Senior Research Fellows publish about the same as Professors. This is partly explained by the nomenclature applied to research-only positions. Research Fellows are often postdocs who are yet to start on the academic ladder, whereas Senior Research Fellows are often longer-term, experienced staff members.

Are there differences by gender?

The differences in output between males and females are significant, as shown in Table 1. Overall, males produce about one third more than females. Part of this gender difference is due to the fact that women predominantly occupy lower academic positions. When men and women within the same rank are compared, a more complex picture emerges (see Figure A-2). Looking at both means and medians, women publish slightly more than men at the Lecturer level - at which they also outnumber men. If only medians are taken into account, women publish more than men at the Associate Professor level too - which may mean that some have become "stuck" at that level and 
have not been promoted to Professor. But men publish more than women at every other rank, and based on all other metrics. The productivity of women falls slightly at Professor level compared to Associate Professor level. Publication means and medians within the same gender also vary, especially among Associate Professors and Professors. This suggest the presence of a few highly productive outliers in the professorial ranks, which are male-dominated.

What impact factors do the most popular peer-reviewed planning journals have?

The most popular journals where Australian planning academics have published are shown in Table A-3, along with their impact factors. Even though the list contains some of the top journals in the field, impact factors are relatively low when compared with other disciplines. They range from 0.69 to 2.56 , and many journals on the list, although highly regarded, do not have an impact factor. The full list of journals indicates substantial diversity in the field. In addition to traditional outlets such as Cities and Environment and Planning, planning-related research has been published in journals as far apart as Journal of Epidemiology and Community Health (health-focused), Ocean and Coastal Management (environment-focused), Applied Mechanics and Materials (engineeringfocused), Tourism Review International (tourism-focused), Progress in Human Geography (geography-focused), and Gender, Place and Culture (gender-focused). A recent study over approximately the same time period (using Scopus data) found that most academics have tended to publish in Australian Planner (official journal of the Planning Institute Australia), reflecting a culture of trying to communicate research findings to practitioners (Byrne 2017).

\section{Citations}

How often is the work of planning academics cited?

The outputs of Australian planning academics have been cited 103,231 times between 2006 and 2016, as shown in Table A-4. However, without comparable international benchmarks, we do not know whether this statistic is significant. ${ }^{10}$ Some key findings are provided below:

- The median number of citations per person is 188 .

- The mean number of citations per person is 527.

- The mean number of citations per person per year is 48 .

The large difference between the mean and the median suggests the presence of a few academics, whose work has attracted a significantly larger number of citations than the rest. As with the number of publications discussed above, in some cases a single faculty member has contributed a disproportionate number of citations.

\section{What variances are there by institutional standing and why?}

While constituting $31 \%$ of the total staff, planning academics in Go8 universities contributed 44\% of the total citations during the study timeframe. The median and mean citations in Go8 universities are 400 and 698 respectively. In other words, the Go8 median is more than twice as high as the overall median. The mean number of citations per person per year is 64 .

The University of Melbourne and the University of Western Australia consistently ranked in the top five based on all citation metrics - although the University of Western Australia did not consistently rank in the top five based on publication metrics. As with publication counts, only four Go8 universities (out of six with planning programs) are among the top ten in terms of total citations: University of New South Wales, University of Melbourne, University of Western 
Australia, and University of Queensland. Planning departments producing the most highly citied publications are in the top universities internationally - based on the Times of Higher Education index (see Table A-5).

How does impact (citation counts) change as academics progress through their careers?

Citation counts increase as academics progress along their career, almost doubling from one academic level to the next (see Figure 4) - unlike publications, which tend to plateau (Figure 5). As planning academics become more established and form a broader network, their papers tend to be cited more frequently. Another explanation might be that as academics become more experienced, they learn to subordinate their curiosity about particular research issues to "fashionable" topics, which are more likely to attract citations, or specialise in specific fields. But overall, at the university level, the relationship between publications and citations is relatively strong, as shown by a simple linear regression (Figure A-3). Planning schools with more productive staff will attract more citations over time.

Are there differences by gender?

The same gender gaps seen in publications persist in citation metrics; the gaps are as pronounced (see Table 2 and Figure A-4). The work of female planning academics tends to attract fewer citations than male academics. Patriarchal structures that undervalue women are a potential factor, and/or males may cite themselves (and each other) more often. Only at Associate Professor level (median only) do women appear to outperform men. This may mean that some highly performing women are "stuck" at this level and have not been promoted to Professor. This is likely due to a failure to attract research grants - another important criterion for promotion in Australian universities. Grant winning may be a function of both male-dominance in awarding agencies and of senior male academics being less encumbered by gendered domestic disparities (e.g., child care).

The Australian Research Council (ARC) - the largest and most prestigious public research funding body in Australia, which provides the lion's share of funding for planning research - is notoriously gender-biased. While males were the lead investigators on 59 'urban and regional planning' ARC grants between 2010 and 2018, females only led 32 grants. Although differences are small among lecturers, the "funding gender gap" broadens considerably at the professorial levels. Male planning professors hold 6.4 times as many ARC grants as female planning professors, although there are only 2.7 times more male professors than female professors. This gender gap might be due to the fact that currently, in the ARC College of Experts, which evaluates grant applications, only 70 of the 176 members are female (Pojani et al. 2018).

How does Australia compare to major centres of planning scholarship, such as the United States?

To place the Australian situation in perspective, the median citation metrics are compared with those of planning academics in the US (Sanchez 2017; 2016). Table 4 shows the top ten universities in the respective countries in terms of median citations. In Australia, the average level of citations per person is much lower than in the US. Comparisons are difficult because research funding, workloads (e.g., teaching requirements) and expectations for scholarship differ between the two countries and between planning programs within each country. However, this large difference in the average level of citations per person might be partly explained by the fact that the US has a population that is 14 times larger than Australia, and thus has a much larger "domestic market" of planning issues and planning academics who cite each other's work. Australia's 
geographical isolation and lean research funding has tended to preclude high levels of international planning research. Our comparisons contrast with those produced by the ARC in its latest Excellence in Research (ERA) report (Table A-5).

\section{Bibliometrics: Google Scholar vs Scopus}

Table A-6 shows that all the metrics reported by Scopus are much lower than the metrics reported by Google Scholar. The total number of publications reported by Scopus (for all planning schools) is less than half the number reported by Google Scholar. Similarly, for total citations, the number reported by Scopus is less than half the number reported by Google Scholar.

Individually, the most striking example is University of New South Wales (UNSW), where citation counts differ between Google Scholar and Scopus by around 12,000. Curtin University and the University of Tasmania have a higher citation impact based on Scopus data than leading Go8 universities, despite their small faculties and modest publication numbers. Macquarie University and the University of Queensland have the highest citation counts in Scopus. Notably, at the University of Queensland, nearly 60\% of the citations captured by Scopus have been contributed by a single academic (who departed from the program after these data were collected).

Based on these findings we conclude that employing Scopus data would be problematic for planning academics who work in large interdisciplinary schools, which combine non-professional disciplines. The publications produced by geography, political science, or environmental management academics are more likely to be included in Scopus, thus disadvantaging planning academics because faculty administrators might not recognise the difference between databases. This is a critical issue that can affect opportunities for promotion and tenure.

\section{Discussion and Conclusion}

There are four main findings of this benchmarking study: (a) wide gender gaps exist in Australian planning academia; (b) the mean number of publications is 36/person or 3/person/year; (c) the mean number of citations is 527/person or 48/person/year; and (d) planning journal impact factors are low. There are some observable institutional differences. In Go8 universities, all metrics are much higher than average. However, not all Go8 universities are among the top ten in terms of publications and citations.

Productivity is not solely a function of career trajectory. While the number of publications increases as academics progress through the ranks, academic output tends to plateau once individuals reach the top rank of Professor. In contrast, citation counts increase steadily as academics progress along their career, nearly doubling from one academic level to the next. However, overall a strong statistical relationship exists between the number of publications and citations. While planning academics publish in a diverse range of journals, the impact factors of those journals are generally low - ranging from 0.69 to 2.56 . Furthermore, many reputable journals do not have an impact factor.

What constitutes a productive Australian planning academic is also configured by gender. All metrics (publications, citations, grants) are lower for women than for men. While women are entering the profession in larger numbers than men, planning programs may have emphasized the retention and/or promotion of men, and this has translated into much higher numbers of men in the professorial ranks. Alternatively, this finding may reflect a context in which male academics occupy higher ranks because they are older and more experienced (having been hired in the past, 
when conditions were different). Also, women are underrepresented on the ARC College of Experts, which evaluates grant applications (Pojani et al. 2018). These patterns indicate that significant institutional barriers may remain, potentially hindering female academics' chances of tenure and/or promotion. Further research, possibly applying both qualitative and quantitative methods is warranted (e.g., surveys, interviews, ethnography), to precisely identify institutional or structural barriers. Factors differentially impacting productivity might include family/child-rearing responsibilities, workloads, community engagement pastoral care responsibilities, and levels of academic mentoring and sponsorship available to junior female academics.

A sizeable body of research, which has considered gendered patterns in the Australian academy overall (not only planning), provides pointers. ${ }^{11}$ Various commentators have suggested that the academy is a hostile work environment for women. The shift in the 1990s from collegial to managerial decision-making has entrenched the gendered character of university power relations and contributed to the predominance of women in the lower ranks. Women just beginning or resuming their careers (e.g., after maternity leave) are particularly vulnerable. As a consequence, not enough women remain in higher education. Lacking critical mass, senior female academics are unable to impact on management culture, while at the same time early-career female academics end up underprovided with networks, mentoring, and encouragement. Even women who reach senior levels encounter the power of the male hegemony that is prepared to accommodate some women, but not to have its dominance challenged (Asmar 1999; White 2001).

The average level of citations per person is much lower in Australia than in the US. Disparities in granting success between the two countries may explain this difference - in addition to the much larger size of the profession in the US. In Australia, the Australian Research Council (ARC) is the main funder of planning research, and between 2006 and 2016, a majority (61\%) of planning academics did not attract any ARC grants (ARC 2016; Pojani et al. 2018). This situation contrasts with the US, where most funding for planning comes from sources other than the National Science Foundation (the US equivalent of ARC), and a significantly higher level of financial support is provided to planning (Troy 2013).

These findings have the potential to inform university administrators about the problematic use of some comparative bibliometric data in performance review, tenure, and promotion activities. Our findings also enable comparison between the research productivity of Australian planning academics and those internationally. It must be noted though, that while we have conducted a practical study based on metrics, we do not advocate that such metrics remain the primary enumerator of planning research productivity. The quality and value of research cannot be measured or fully captured through numbers alone. Recruitment and promotion panels at universities would do well to read academics' published work - ideally under conditions of anonymity - appraising research quality against diverse criteria, not relying solely on metrics as a shorthand proxy for quality. While difficult and time-consuming, such evaluation practices are necessary to counter the shortcomings of metrics-based assessments.

\section{References}

Aguillo, Isidro. 2012. "Is Google Scholar Useful for Bibliometrics? A Webometric Analysis." Scientometrics 91(2):343-351.

Asmar, Christine. 1999. "Is there a Gendered Agenda in Academia? The Research Experience of Female and Male PhD Graduates in Australian Universities." Higher Education 38:255-273. 
Australian Research Council. 2016. "ARC Grants." Link: rms.arc.gov.au/RMS/Report/Download/Report/d6b15b2b-3a50-4021-8e6f-6c7ef1cba553/0. Retrieved: 19 January 2016.

Bornmann, Lutz, Hans-Dieter, Daniel. 2008. "What Do Citation Counts Measure? A Review of Studies on Citing Behavior.” Journal of Documentation 64(1):45-80.

Bornmann, Lutz, Hans-Dieter, Daniel. 2009. "The State of h-Index Research. Is the h-Index the Ideal Way to Measure Research Performance?" EMBO Reports 10(1):2-6.

Brembs, Björn, Katherine Button, Marcus Munafò. 2013. "Deep Impact: Unintended Consequences of Journal Rank." Frontiers in Human Neuroscience doi:10.3389/fnhum.2013.00291.

Batterbury, Simon and Byrne, Jason. 2017. “Australia: Reclaiming the Public University” Social Epistemology Review and Reply Collective http://wp.me/p1Bfg0-3FV 23-32.

Byrne, Jason. 2017. "Tracing the History of Australian Planning Research and Its Influence on Practice" in K., Vella., N. Sipe, and T. Schooens (eds.), The Routledge Handbook of Australian Urban and Regional Planning, 335-353. New York: Routledge.

Campbell, Philip. 2008. "Escape from the Impact Factor." Ethics in Science and Environmental Politics 8:5-7.

Checkoway, Barry. 1997. "Reinventing the Research University for Public Service." Journal of Planning Literature 11(3):307-319.

Connell, Raewyn. 2015. "Australian Universities under Neoliberal Management: The Deepening Crisis." International Higher Education 81:23-25.

Dodd, Tim. 2017 "Education exports are worth $\$ 28$ billion a year, nearly 20pc more than we thought". Australian Financial Review, https://www.afr.com/leadership/education-exports-are-worth-28billion-a-year-nearly-20pc-more-than-we-thought-20171005-gyvc8v, accessed September 3, 2018.

Frank, Nancy. 2008. "Measuring Public Service: Assessment and Accountability - To Ourselves and Others.” Journal of Planning Education and Research 27(4):499-506.

Harzing, Anne-Wil. 2010. The Publish or Perish Book: Your Guide to Effective and Responsible Citation Analysis. Melbourne: Tarma Software Research.

Hicks, D. 2012. "Performance-based university research funding systems". Research Policy 41(2):251-261.

Hirsch, Jorge. 2005. "An Index to Quantify an Individual's Scientific Research Output." Proceedings of the National Academy of Sciences of the United States of America 102(46):16569-16572.

Hurt, Christine, Tung, Yin. 2006. "Blogging While Untenured and Other Extreme Sports." Washington University Law Review 84(5):1235-1255.

Hyland, Ken. 2016. Academic Publishing: Issues and Challenges in the Construction of Knowledge. Oxford: Oxford University Press.

Innovative Research Universities. 2018. Media Release: Australian Researchers' Productivity Boom. July 12, 2018, https://www.iru.edu.au/news/australian-researchers-productivity-boom/ (accessed 
September 3, 2018).

Jöns, H., Hoyler, M. 2013. “Global Geographies of Higher Education: The Perspective of World University Rankings”. Geoforum, 46:45-59.

Kousha, Kayvan, Mike Thelwall. 2008. "Sources of Google Scholar Citations outside the Science Citation Index: A Comparison between Four Science Disciplines.” Scientometrics 74(2):273294.

Kousha, Kayvan, Mike Thelwall, Somayeh, Rezaie. 2010. "Using the Web for Research Evaluation: The Integrated Online Impact Indicator." Journal of Informetrics 4(1):124-135.

Krumholz, Norman. 1986. "From Planning Practice to Academia." Journal of Planning Education and Research 6(1):60-65.

Martin, Wachs. 1994. "The Case for Practitioner Faculty." Journal of Planning Education and Research 13(4):290-296.

Pojani, Dorina, Olvera-Garcia, Jaime, Byrne, Jason, Sipe, Neil. 2018 “Australian cities are crying out for better planning, but the research funding is missing." The Conversation February 23.

Postman, Neil. 1993. Technopoly: The Surrender of Culture to Technology. New York: Vintage.

Priem, Jason, Dario Taraborelli, Paul Groth, Camero,n Neylon. 2010. “Altmetrics: A Manifesto.” Link: altmetrics.org/manifesto Retrieved: 9 November 2016.

Riordan, Sarah. 2011. "Paths to Success in Senior Management." In B. Bagilhole and K. White (eds.), Gender, Power and Management: A Cross Cultural Analysis of Higher Education, pp. 110-139. Basingstoke: Palgrave Macmillan.

Sanchez, Tom. 2014. "Academic Visibility for Urban Planning and the Webometric Future." Journal of the World Universities Program 6(2):37-52.

Sanchez, Tom. 2017. "Faculty Performance Evaluation Using Citation Analysis: An Update." Journal of Planning Education and Research 37(1):83-94.

Sanchez, Tom. 2016. "Planning Citation Analysis: Update." Link: http://tomwsanchez.com/planningcitation-analysis-update/ Retrieved: 13 September 2016.

Savonick, Danica, Davidson, Cathy. 2017. "Gender Bias in Academe: An Annotated Bibliography of Important Recent Studies." Link: blogs.Ise.ac.uk/impactofsocialsciences/2016/03/08/gender-bias-inacademe-an-annotated-bibliography/\#new. Retrieved 28/6/2017.

Simons, Kai. 2008. “The Misused Impact Factor.” Science 322(5899):165.

Spain, Daphne. 1992. "Creating and Defending Links between Teaching, Research, and Public Service.” Journal of Planning Education and Research 12(1):77-79.

Stevens, Garry. 1990. "An Alliance Confirmed Planning Literature and the Social Sciences." Journal of the American Planning Association 56(3):341-349.

Stiftel, Bruce, Deden Rukmana, Bhuiyan Alam. 2004. "A National Research Council-Style Study." Journal of Planning Education and Research 24:6-22.

Taylor, Paul, Braddock, Richard. 2007. "International University Ranking Systems and the Idea of University Excellence". Journal of Higher Education Policy and Management, 29(3):245260. 
Thoreau, Henry-David. 1854. Walden, and on the Duty of Civil Disobedience. Boston: Ticknor and Fields.

Wiewel, Wim, Carlson, Virginia, Friedman. Suzanne. 1996. "Planning the New Urban University: The Role of Planning Departments." Journal of Planning Education and Research 16(2):127135 .

White, Kate. 2001. "Women in the Professoriate in Australia." International Journal of Organisational Behaviour 3(2):64-76. 


\section{Notes}

${ }^{1}$ Group of Eight (Go8) is a coalition of research-intensive Australian universities. It includes: University of Western Australia, Monash University, Australian National University, University of Adelaide, University of Queensland, University of Melbourne, University of New South Wales, and University of Sydney. See go8.edu.au.

${ }^{2}$ The concept of grading students' work quantitatively is relatively recent too (late $18^{\text {th }}$ century). A few universities and colleges are now eschewing grades in favor of qualitative feedback and simple pass/fail evaluations.

${ }^{3}$ Formerly known as Thomson Reuters.

${ }^{4}$ The analysis did not account for the fact that some academics may not have been employed in their current job during the entire study timeframe.

${ }^{5}$ A handful of programs follow the US model and combine levels A through C into a single rank - Assistant Professor. For this study, data for Assistant Professors were merged with data for Lecturers.

${ }^{6}$ For the purpose of this study, data for "Research Associates" was combined with data for "Research Fellows" as there was a single researcher listed in the "Research Associate" category.

${ }^{7}$ A similar study identified 23 programs and 164 staff members (Byrne 2017). However, that study excluded research-only staff and considered only planning academics on a "standard" appointment, which in Australia typically consists of $40 \%$ research, $40 \%$ teaching, and $20 \%$ service.

${ }^{8}$ These include the following: (1) University of Adelaide, Adelaide, Centre for Housing, Urban and Regional Planning; (2) Griffith University, Brisbane and Gold Coast, Cities Research Centre; University of Melbourne, Melbourne, Melbourne Sustainable Society Institute; (3) University of New South Wales, Sydney, City Futures Research Centre; (5) University of Sydney, Sydney, Planning Research Centre; (6) University of Western Australia, Perth, Centre for Regional Development; and (7) RMIT University, Melbourne, Centre for Urban Research. The latter is the largest urban research center in Australia, with 20 fellows. Many staff members in these centers are not planners but rather geographers, environmental scientists, economists, etc., and were therefore excluded from this study. Some staff members listed as research fellows in these centers (e.g., at RMIT, Griffith University, University of Melbourne, and University of Sydney) are also listed as lecturers or professors in the respective planning departments.

${ }^{9}$ It is well possible that a correlation exists. For example, in programs that have large class sizes or intensive studio teaching, the faculty might be left with little time for research.

${ }^{10}$ Sanchez (2017) provides comparable benchmarks for the US; however, these appear to reflect career rather than a decade of work.

${ }^{11}$ Two female academics, Danica Savonick and Cathy Davidson, have compiled an annotated biography of important recent studies on gender bias in academia, in Australia and elsewhere:

blogs.1se.ac.uk/impactofsocialsciences/2016/03/08/gender-bias-in-academe-an-annotated-bibliography/\#new 


\section{Tables}

Table 1. Publications and citations by gender.

\begin{tabular}{lcccc}
\hline Totals & $\begin{array}{c}\text { Mean no. of } \\
\text { publications } \\
\text { per person }\end{array}$ & $\begin{array}{c}\text { Median no. of } \\
\text { publications } \\
\text { per person }\end{array}$ & $\begin{array}{c}\text { Mean no. of } \\
\text { citations per } \\
\text { person }\end{array}$ & $\begin{array}{c}\text { Median no. of } \\
\text { citations per } \\
\text { person }\end{array}$ \\
\hline Male & 42 & 32 & 703 & 360 \\
Female & 28 & 22 & 308 & 148 \\
Gender gap & $33 \%$ & $31 \%$ & $56 \%$ & $59 \%$ \\
\hline
\end{tabular}

Note: The gender gap was calculated based on the formula: (male-female)/male. 
Table 2. Comparison with the USA.

\begin{tabular}{lllc}
\hline & & \multicolumn{2}{c}{$\begin{array}{c}\text { Median no. of citations per } \\
\text { planning academic }\end{array}$} \\
US University & Australian University & USA & Australia \\
\hline Columbia University & James Cook University & 2,390 & 800 \\
University of Minnesota & University of Melbourne & 2,252 & 680 \\
University of California, Los Angeles & University of Western Australia & 1,994 & 471 \\
Harvard University & University of Adelaide & 1,577 & 382 \\
New York University & University of New South Wales & 1,551 & 363 \\
Wayne State University & University of Queensland & 1,340 & 361 \\
University of Southern California & Queensland Uni. of Technology & 1,244 & 353 \\
University of Toronto & Macquarie University & 1,097 & 323 \\
Arizona State University & RMIT & 1,064 & 290 \\
University of Maryland & University of Technology, Sydney & 1,056 & 226 \\
\hline
\end{tabular}

Note on ranking

University among the top 100 based on the Times of Higher Education (THE) index

(https://www.timeshighereducation.com/world-university-rankings)

*US and University of Toronto data are based on Sanchez (2016a; 2016b). 


\section{Figures}

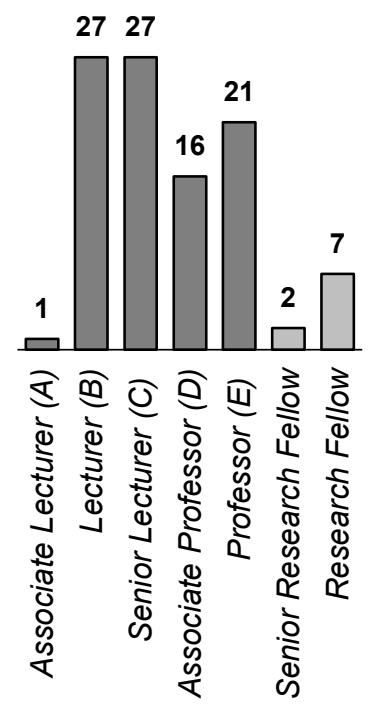

Figure 1. Percentage of planning staff by rank. 


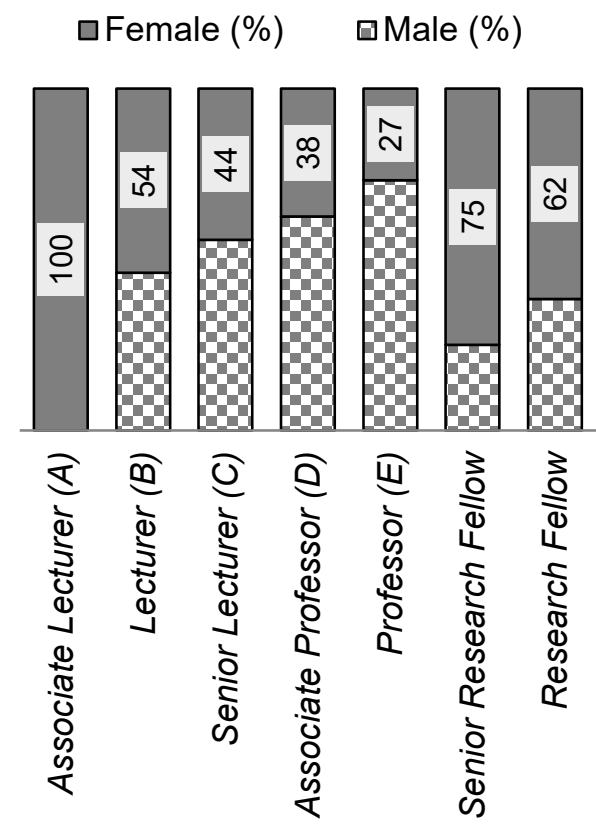

Figure 2. Gender division by academic rank. 


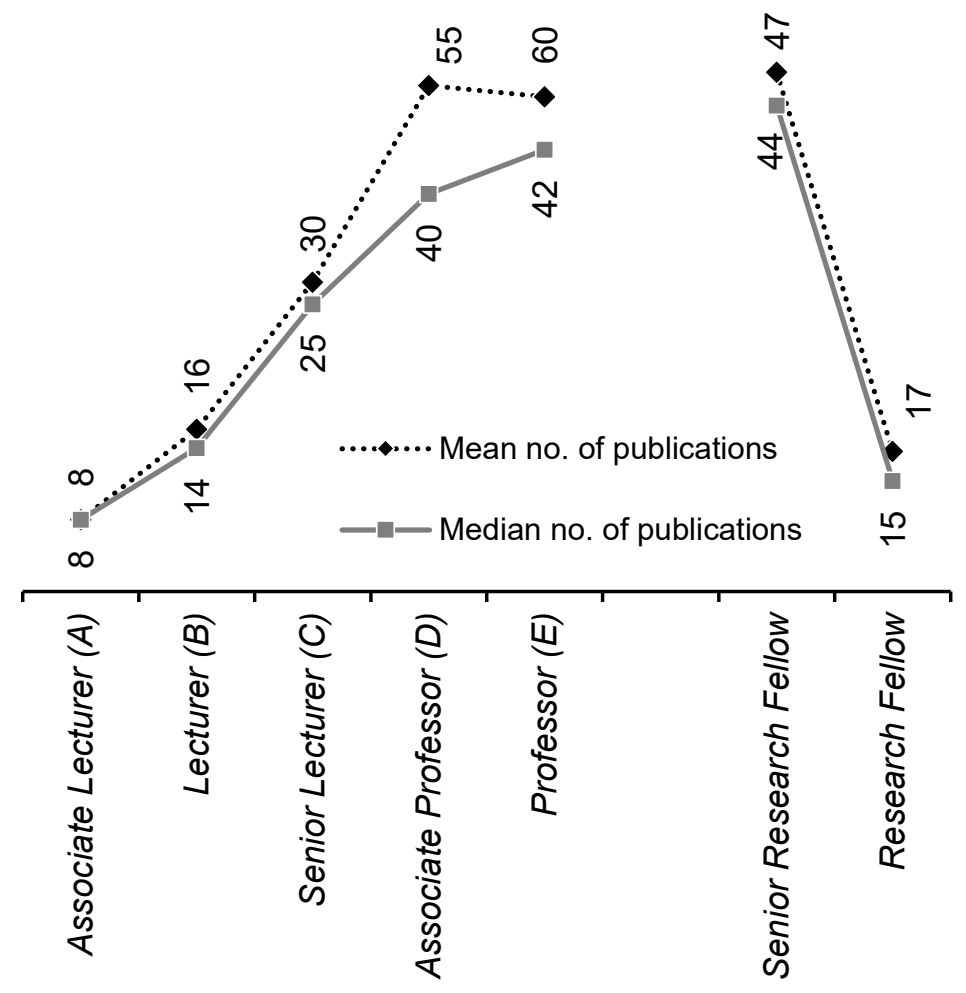

Figure 3. Publications by rank. 


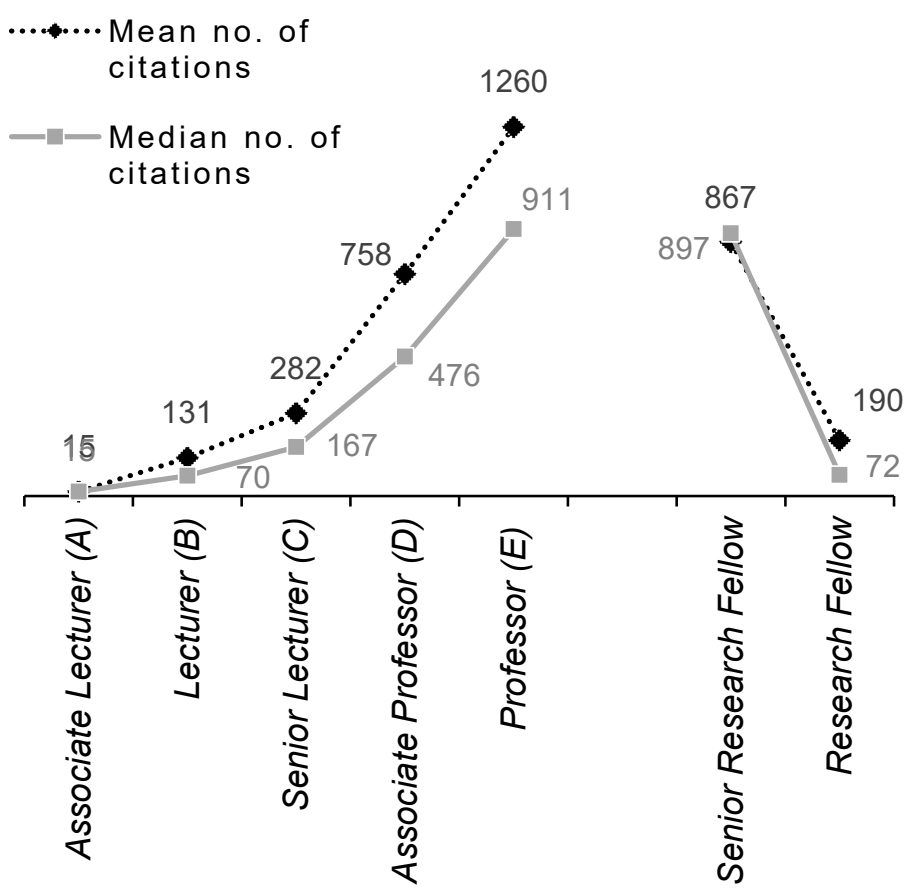

Figure 4. Citations by rank. 


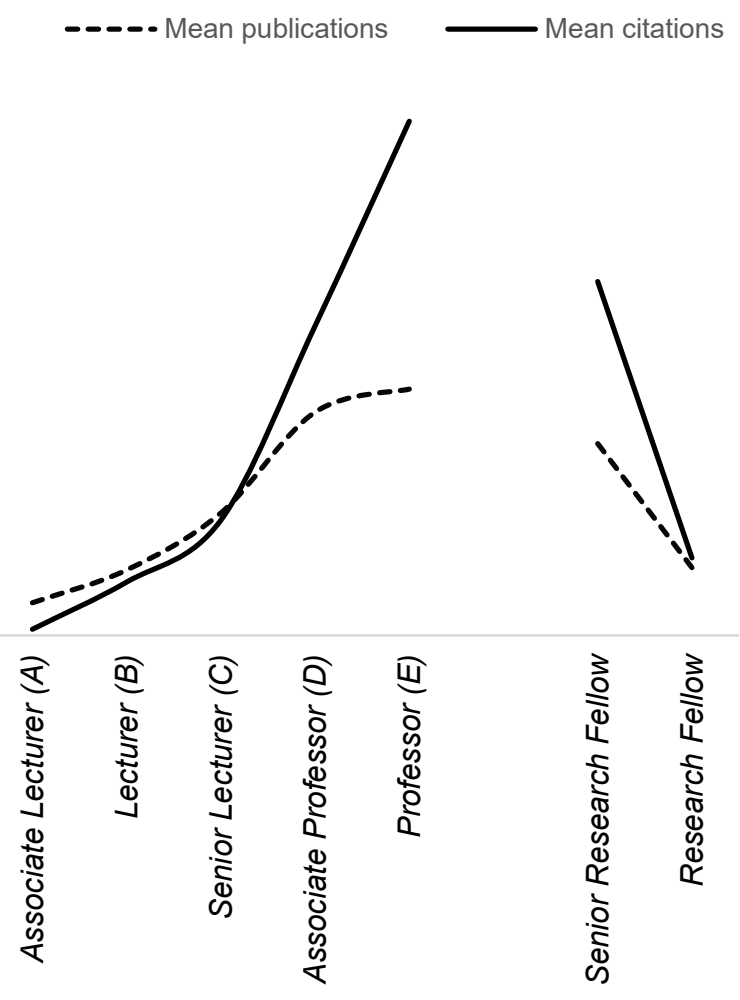

Figure 5. Metric trends by rank. 


\section{The following Appendices to be published as supplementary material (online only).}




\section{Appendix (Tables)}

Table A-1. Planning programs and staff.

\begin{tabular}{|c|c|c|c|c|}
\hline No. & University & City \& State & $\begin{array}{c}\text { Total } \\
\text { programs }\end{array}$ & Total staff \\
\hline 1 & University of New South Wales ${ }^{* *}$ & Sydney, NSW & 2 & 21 \\
\hline 2 & Griffith University*** & Brisbane/Gold Coast, QLD & 3 & 18 \\
\hline 3 & RMIT University & Melbourne, VIC & 3 & 16 \\
\hline 4 & Macquarie University & Sydney, NSW & 2 & 14 \\
\hline 5 & University of Western Australia & Perth, WA & 2 & 12 \\
\hline 6 & Western Sydney University & Sydney, NSW & 3 & 12 \\
\hline 7 & University New England & Armidale, NSW & 2 & 10 \\
\hline 8 & Curtin University & Perth, WA & 2 & 9 \\
\hline 9 & University of Melbourne & Melbourne, VIC & 2 & 9 \\
\hline 10 & University of Queensland & Brisbane, QLD & 2 & 9 \\
\hline 11 & Queensland University of Technology & Brisbane, QLD & 1 & 9 \\
\hline 12 & University of Sydney & Sydney, NSW & 3 & 8 \\
\hline 13 & Deakin University & Melbourne, VIC & 2 & 6 \\
\hline 14 & James Cook University & Townsville, QLD & 2 & 6 \\
\hline 15 & University of South Australia & Adelaide, SA & 3 & 6 \\
\hline 16 & La Trobe University & Melbourne, VIC & 2 & 5 \\
\hline 17 & University of Tasmania & Hobart, TAS & 1 & 5 \\
\hline 18 & University of Technology Sydney & Sydney, NSW & 1 & 5 \\
\hline 19 & Bond University & Gold Coast, QLD & 2 & 4 \\
\hline 20 & University of Canberra & Canberra, ACT & 2 & 3 \\
\hline 21 & University of Sunshine Coast & Sunshine Coast, QLD & 2 & 3 \\
\hline 22 & University of Adelaide & Adelaide, SA & 2 & 2 \\
\hline 23 & Edith Cowan University & Perth, WA & 1 & 2 \\
\hline \multirow[t]{2}{*}{24} & Southern Cross University & Lismore, QLD & 1 & 2 \\
\hline & Total & & 48 & 196 \\
\hline
\end{tabular}

*May include Bachelor, Master, and PhD programs.

${ }^{* *}$ In reporting data for the University of New South Wales (UNSW), we combine planning program staff and City Futures Research Centre (CFRC) staff. This is subject to a number of caveats. While CFRC is a significant resource for planning at UNSW and many CFRC staff members contribute to planning research rankings, some do not. While the UNSW group of urban researchers is probably the largest in the state, if only the planning program was included in the calculations, numbers would be lower than at Griffith University or RMIT. Overall, the UNSW planning team (teaching and research) is relatively modestly-sized.

${ }^{* * *}$ Griffith University has recently experienced voluntary retirements and the core planning staff who both teach and undertake research is now just 8 faculty. 
Table A-2. Publications (2006-2016).

\begin{tabular}{|c|c|c|c|c|c|c|c|}
\hline 榇 & University & $\begin{array}{c}\text { No. of } \\
\text { faculty } \\
\text { members }\end{array}$ & $\begin{array}{l}\text { Total no. of } \\
\text { publications }\end{array}$ & $\begin{array}{l}\text { Range of } \\
\text { publications } \\
\text { per person }\end{array}$ & $\begin{array}{c}\text { Median no. of } \\
\text { publications / } \\
\text { person }\end{array}$ & $\begin{array}{l}\text { Mean no. of } \\
\text { publications } \\
\text { / person }\end{array}$ & $\begin{array}{l}\text { Mean no. of } \\
\text { publications / } \\
\text { person / year }\end{array}$ \\
\hline 1 & University of New South Wales & 21 & 1065 & $267-7$ & 26.0 & 50.7 & 5 \\
\hline 2 & University of Melbourne & 9 & 687 & $159-15$ & 70.0 & 76.3 & 7 \\
\hline 3 & Griffith University & 18 & 642 & $105-0$ & 33.0 & 35.6 & 3 \\
\hline 4 & Queensland U. of Technology & 9 & 456 & $228-6$ & 28.0 & 50.6 & 5 \\
\hline 5 & Macquarie University & 14 & 442 & $70-3$ & 27.5 & 31.5 & 3 \\
\hline 6 & RMIT & 16 & 439 & $63-1$ & 26.5 & 27.4 & 2 \\
\hline 7 & Western Sydney University & 12 & 387 & $92-12$ & 22.5 & 32.3 & 3 \\
\hline 8 & University of Western Australia & 12 & 340 & $56-8$ & 26.0 & 28.3 & 3 \\
\hline 9 & University of Queensland & 9 & 322 & $71-11$ & 37.0 & 35.8 & 3 \\
\hline 10 & University of South Australia & 6 & 283 & $93-7$ & 49.0 & 47.0 & 4 \\
\hline 11 & University of Sydney & 8 & 259 & $91-3$ & 23.0 & 32.3 & 3 \\
\hline 12 & James Cook University & 6 & 245 & $106-6$ & 18.0 & 40.8 & 4 \\
\hline 13 & Curtin University & 9 & 244 & $56-3$ & 31.0 & 27.1 & 2 \\
\hline 14 & University of New England & 10 & 242 & $73-9$ & 16.5 & 24.2 & 2 \\
\hline 15 & University of Technology, Sydney & 5 & 215 & $90-18$ & 39.0 & 43.0 & 4 \\
\hline 16 & University of Tasmania & 5 & 178 & $75-3$ & 28.0 & 35.6 & 3 \\
\hline 17 & University of Sunshine Coast & 3 & 148 & $82-26$ & 40.0 & 49.3 & 4 \\
\hline 18 & La Trobe University & 5 & 104 & $30-15$ & 19.0 & 20.8 & 2 \\
\hline 19 & Deakin University & 6 & 103 & $39-5$ & 13.5 & 17.1 & 2 \\
\hline 20 & Bond University & 4 & 90 & $36-2$ & 24.0 & 16.0 & 2 \\
\hline 21 & University of Canberra & 3 & 62 & $38-10$ & 14.0 & 20.6 & 2 \\
\hline 22 & University of Adelaide & 2 & 60 & $42-18$ & 30.0 & 30.0 & 3 \\
\hline 23 & Southern Cross University & 2 & 17 & $13-4$ & 8.5 & 8.5 & 0.8 \\
\hline \multirow[t]{2}{*}{24} & Edith Cowan University & 2 & 8 & $4-4$ & 4.0 & 2.0 & 0.2 \\
\hline & Total & 196 & 7038 & 267-0 & 26.2 & 36 & 3 \\
\hline
\end{tabular}

Note:

\begin{tabular}{l|l}
$\begin{array}{ll}\text { Note: } \\
\text { Consistently among the top five }- \text { based on total number of publications, median and mean number of publications per } \\
\text { Go8 }\end{array}$ \\
$\begin{array}{ll}\text { green } \\
\text { text }\end{array}$ & minimums and maximums
\end{tabular}


Table A-3. Most popular journals* ranked by impact factors.

\begin{tabular}{lc}
\hline Journal name & Impact Factor (IF) \\
\hline Applied Geography & 2.56 \\
Journal of Rural Studies & 2.20 \\
Journal of Transport Geography & 2.09 \\
Cities & 2.05 \\
Habitat International & 2.02 \\
Urban Studies & 1.93 \\
Transport Policy & 1.52 \\
Environment and Planning A & 1.46 \\
Planning Theory & 1.40 \\
Geographical Research & 1.35 \\
Australian Geographer & 1.19 \\
Urban Policy and Research & 0.89 \\
Australasian Journal of Environmental Management & 0.69 \\
Australian Planner & No IF \\
Built Environment & No IF \\
Local Environment & No IF \\
Planning Perspectives & No IF \\
Planning Practice \& Research & No IF \\
Planning Theory and Practice & No IF \\
Town Planning Review & No IF \\
\hline
\end{tabular}

${ }^{*}$ Defined as those journals in which Australian planning academics have published three or more papers. Source: Clarivate Analytics database. 
Table A-4. Programs rank-ordered by citations per person (2006-2016).

\begin{tabular}{|c|c|c|c|c|c|c|c|}
\hline Rank & University & $\begin{array}{c}\text { No. of } \\
\text { faculty } \\
\text { members }\end{array}$ & $\begin{array}{l}\text { Total no. } \\
\text { of } \\
\text { citations }\end{array}$ & $\begin{array}{l}\text { Range of } \\
\text { citations } \\
\text { per } \\
\text { person }\end{array}$ & $\begin{array}{c}\text { Median } \\
\text { no. of } \\
\text { citations } \\
\text { per person }\end{array}$ & $\begin{array}{c}\text { Mean no. } \\
\text { of } \\
\text { citations } \\
\text { per } \\
\text { person } \\
\end{array}$ & $\begin{array}{c}\text { Mean no. } \\
\text { of citations } \\
\text { per person } \\
\text { per year }\end{array}$ \\
\hline 1 & University of New South Wales & 21 & 14232 & $2439-12$ & 363 & 678 & 62 \\
\hline 2 & University of Melbourne & 9 & 10860 & $4362-59$ & 680 & 1207 & 110 \\
\hline 3 & University of Western Australia & 12 & 8729 & 2784-79 & 471 & 727 & 66 \\
\hline 4 & University of New England & 10 & 7804 & $4753-34$ & 140 & 780 & 71 \\
\hline 5 & University of Queensland & 9 & 7543 & $3827-30$ & 361 & 838 & 76 \\
\hline 6 & Macquarie University & 14 & 7326 & $2219-12$ & 323 & 523 & 48 \\
\hline 7 & Western Sydney University & 12 & 7089 & $3164-61$ & 157 & 591 & 54 \\
\hline 8 & Griffith University & 18 & 7048 & $2090-0$ & 118 & 392 & 36 \\
\hline 9 & RMIT & 16 & 5887 & $1378-17$ & 290 & 368 & 33 \\
\hline 10 & Queensland University of Technology & 9 & 5756 & $2972-3$ & 353 & 640 & 58 \\
\hline 11 & James Cook University & 6 & 5153 & $2221-77$ & 800 & 859 & 78 \\
\hline 12 & Curtin University & 9 & 3269 & $1289-0$ & 86 & 363 & 33 \\
\hline 13 & University of Tasmania & 5 & 2953 & $2506-76$ & 186 & 591 & 54 \\
\hline 14 & University of Sydney & 8 & 2823 & $1508-2$ & 144 & 353 & 32 \\
\hline 15 & University of South Australia & 6 & 1565 & $607-1$ & 212 & 261 & 24 \\
\hline 16 & University of Technology, Sydney & 5 & 1450 & $940-0$ & 226 & 290 & 26 \\
\hline 17 & Bond University & 4 & 803 & $477-0$ & 163 & 200 & 18 \\
\hline 18 & University of Adelaide & 2 & 764 & $327-437$ & 382 & 382 & 35 \\
\hline 19 & University of Sunshine Coast & 3 & 705 & $481-104$ & 120 & 235 & 21 \\
\hline 20 & University of Canberra & 3 & 602 & $254-158$ & 190 & 201 & 18 \\
\hline 21 & La Trobe University & 5 & 590 & $225-44$ & 102 & 118 & 11 \\
\hline 22 & Deakin University & 6 & 162 & $84-1$ & 16 & 27 & 2 \\
\hline 23 & Southern Cross University & 2 & 94 & $54-40$ & 47 & 47 & 4 \\
\hline \multirow[t]{2}{*}{24} & Edith Cowan University & 2 & 24 & $15-9$ & 12 & 12 & 1 \\
\hline & Total & 196 & 103,231 & 4753-0 & 188 & 527 & 48 \\
\hline
\end{tabular}

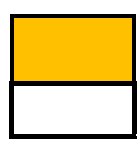

Consistently among the top five - Based on total number of citations, median and mean number of citations per person, and mean number of citations/person/year

green minimums and maximums

text 
Table A-5. Program ranking against international benchmarks.

\begin{tabular}{|c|c|c|c|c|}
\hline Institution & 2010 & 2012 & 2015 & \\
\hline \multicolumn{5}{|l|}{ Curtin University of Technology } \\
\hline \multicolumn{5}{|l|}{ Deakin University } \\
\hline \multicolumn{5}{|l|}{ Griffith University } \\
\hline \multicolumn{5}{|l|}{ La Trobe University } \\
\hline Macquarie University & & & & Legend \\
\hline Monash University & & & & well above world standard \\
\hline Queensland University of Technology & & & & above world standard \\
\hline RMIT University & & & & at world standard \\
\hline Swinburne University of Technology & & & & below world standard \\
\hline University of Melbourne & & & & well below world standard \\
\hline University of New South Wales & & & & no data \\
\hline University of Queensland & & & & University among the top 100 (THE index) \\
\hline \multicolumn{5}{|l|}{ University of South Australia } \\
\hline \multicolumn{5}{|l|}{ University of Sydney } \\
\hline \multicolumn{5}{|l|}{ University of Tasmania } \\
\hline \multicolumn{5}{|l|}{ University of Technology, Sydney } \\
\hline \multicolumn{5}{|l|}{ University of Western Australia } \\
\hline University of Western Sydney & & & & \\
\hline
\end{tabular}

Source: Australian Research Council, Excellence in Research for Australia (ERA) outcomes: www.arc.gov.au/eraoutcomes\#FoR/1205 
Table A-6. Comparison of Google Scholar and Scopus data (2006-2016).

\begin{tabular}{|c|c|c|c|c|c|c|}
\hline & & & Gogg & holar & & \\
\hline$\stackrel{\widetilde{\Phi}}{\mathbb{\complement}}$ & University & No. of faculty members & $\begin{array}{l}\text { Total no. of } \\
\text { publications }\end{array}$ & $\begin{array}{l}\text { Total no. of } \\
\text { citations }\end{array}$ & $\begin{array}{l}\text { Total no. of } \\
\text { publications }\end{array}$ & $\begin{array}{c}\text { Total no. of } \\
\text { citations }\end{array}$ \\
\hline 1 & University of New South Wales & 21 & 1,065 & 14,232 & 413 & 2,705 \\
\hline 2 & University of Melbourne & 9 & 687 & 10,860 & 348 & 3,665 \\
\hline 3 & Griffith University & 18 & 642 & 7,048 & 383 & 3,828 \\
\hline 4 & Queensland University of Technology & 9 & 456 & 5,756 & 224 & 3,053 \\
\hline 5 & Macquarie University & 14 & 442 & 7,326 & 304 & 4,437 \\
\hline 6 & RMIT & 16 & 439 & 5,887 & 262 & 2,348 \\
\hline 7 & Western Sydney University & 12 & 387 & 7,089 & 222 & 2,704 \\
\hline 8 & University of Western Australia & 12 & 340 & 8,729 & 220 & 3,721 \\
\hline 9 & University of Queensland & 9 & 322 & 7,543 & 264 & 4,166 \\
\hline 10 & University of South Australia & 6 & 283 & 1,565 & 84 & 554 \\
\hline 11 & University of Sydney & 8 & 259 & 2,823 & 123 & 990 \\
\hline 12 & James Cook University & 6 & 245 & 5,153 & 79 & 870 \\
\hline 13 & Curtin University & 9 & 244 & 3,269 & 92 & 1,013 \\
\hline 14 & University of New England & 10 & 242 & 7,804 & 181 & 2,896 \\
\hline 15 & University of Technology, Sydney & 5 & 215 & 1,450 & 87 & 434 \\
\hline 16 & University of Tasmania & 5 & 178 & 3,124 & 87 & 1,211 \\
\hline 17 & University of Sunshine Coast & 3 & 148 & 705 & 52 & 381 \\
\hline 18 & La Trobe University & 5 & 104 & 590 & 38 & 281 \\
\hline 19 & Deakin University & 6 & 103 & 162 & 38 & 71 \\
\hline 20 & Bond University & 4 & 90 & 803 & 28 & 220 \\
\hline 21 & University of Canberra & 3 & 62 & 602 & 35 & 207 \\
\hline 22 & University of Adelaide & 2 & 60 & 764 & 48 & 312 \\
\hline 23 & Southern Cross University & 2 & 17 & 94 & 10 & 39 \\
\hline \multirow[t]{2}{*}{24} & Edith Cowan University & 2 & 8 & 24 & 4 & 6 \\
\hline & Total & 196 & 7,038 & 103,402 & 3,626 & 40,112 \\
\hline
\end{tabular}

Note:

$\begin{array}{ll}\begin{array}{ll}\text { Consistently among the top five, for both publications and citations - both in Google Scholar and Scopus } \\ \text { Go8 }\end{array} \\ \begin{array}{ll}\text { green } \\ \text { text }\end{array} & \text { minimums and maximums }\end{array}$ 


\section{Appendix (Figures)}

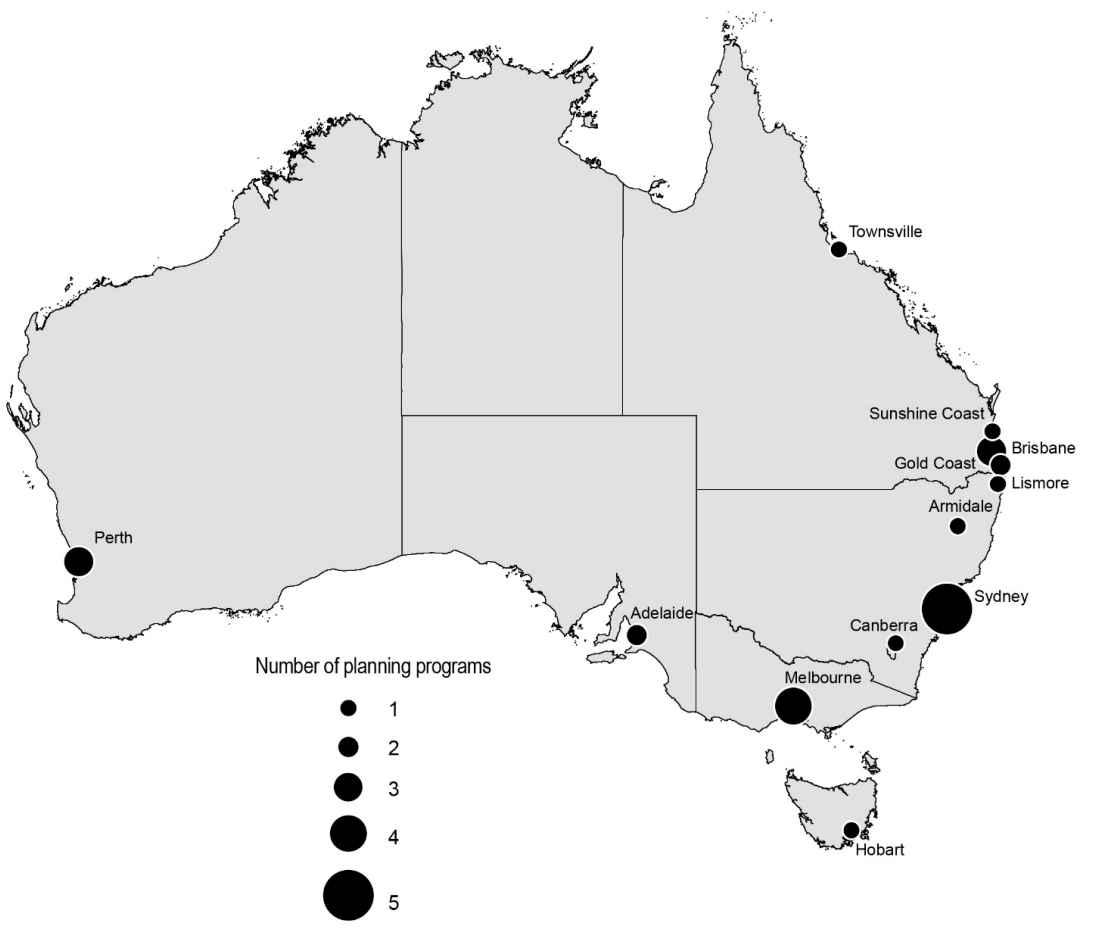

Figure A-1. Location of Australian universities offering planning programs. 


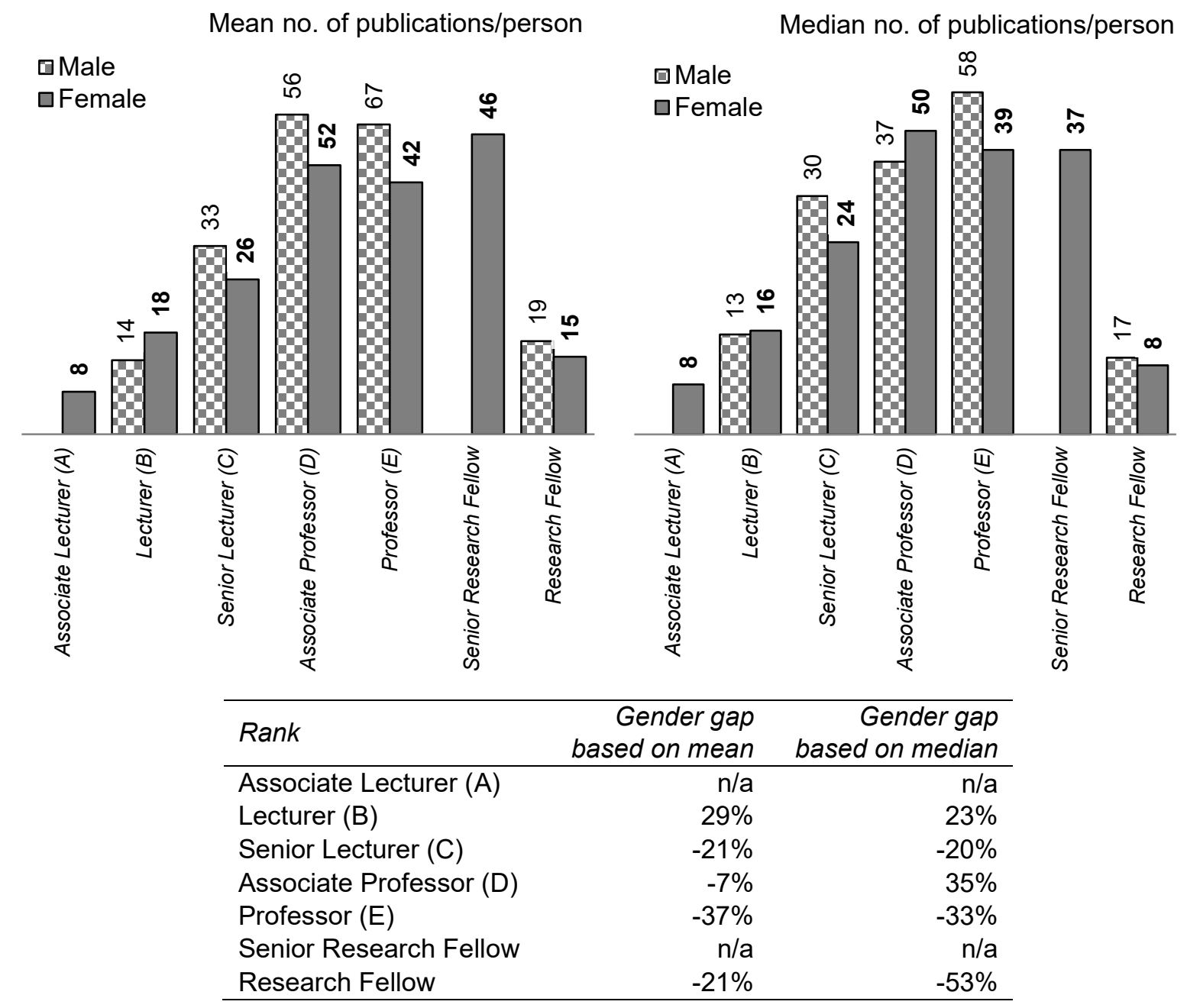

Note: There are no males in the Associate Lecturer (A) category, and there is only one male in the Senior Research Fellow category. The gender gap was calculated based on the formula: (male-female)/male.

Figure A-2. Publications by gender by rank. 


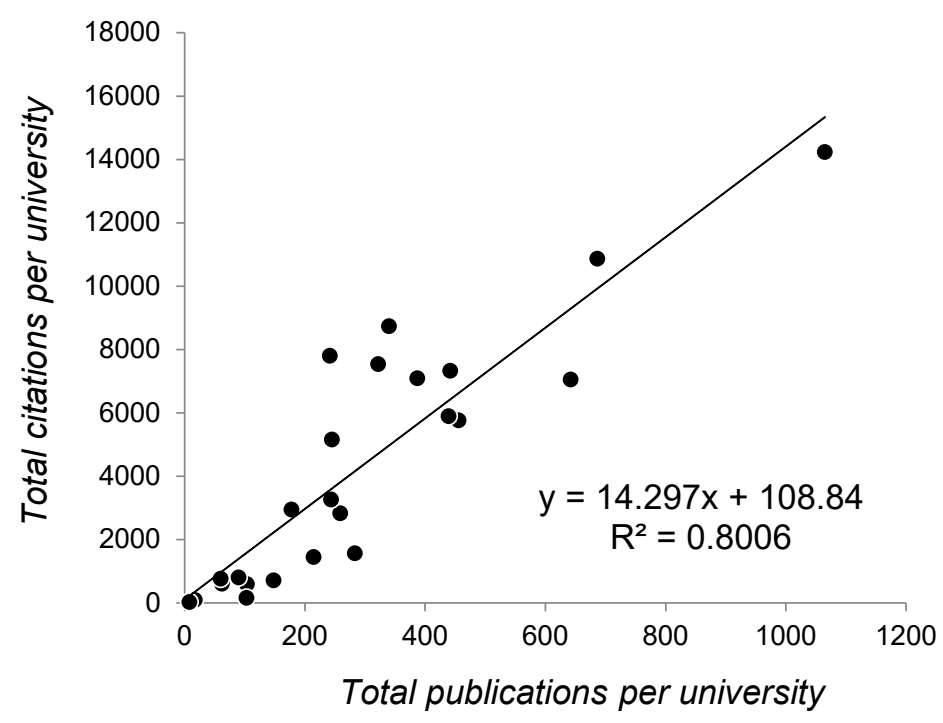

Figure A-3. Relationship between citations and publications per university (planning staff only). 
Mean no. of citations/ person

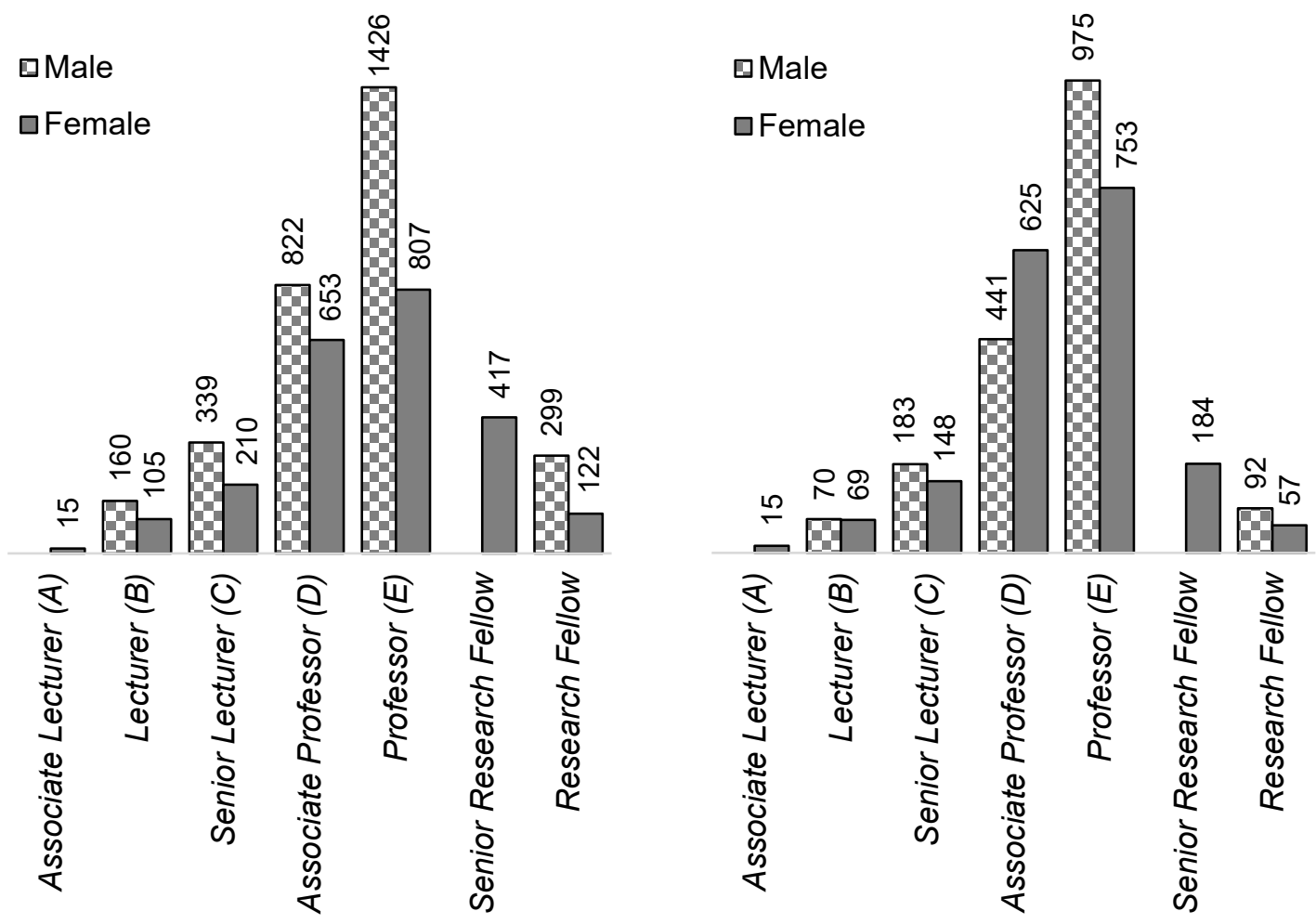

\begin{tabular}{lrr}
\hline Rank & $\begin{array}{r}\text { Gender gap } \\
\text { based on mean }\end{array}$ & $\begin{array}{r}\text { Gender gap } \\
\text { based on median }\end{array}$ \\
\hline Associate Lecturer (A) & & $-1 \%$ \\
Lecturer (B) & $-34 \%$ & $-19 \%$ \\
Senior Lecturer (C) & $-38 \%$ & $42 \%$ \\
Associate Professor (D) & $-21 \%$ & $-23 \%$ \\
Professor (E) & $-43 \%$ & \\
Senior Research Fellow & & $-38 \%$ \\
Research Fellow & $-59 \%$ & \\
\hline
\end{tabular}

Notes: There are no males in the Associate Lecturer $(A)$ category, and only one female academic in this category has a Google Scholar profile. There is only one male in the Senior Research Fellow category. The gender gap was calculated based on the formula: (male-female)/male.

Figure A-4. Citations by gender by rank. 